\title{
Malpositioned Nasogastric Tube
}

${ }^{1}$ Seema Partani , ${ }^{2}$ Anil K Bhiwal

How to cite this article: Partani S, Bhiwal AK. Malpositioned Nasogastric Tube. Res Inno in Anesth 2018;3(1):32.

\section{Source of support: Nil}

\section{Conflict of interest: None}

\section{Sir,}

Insertion of nasogastric tube (NGT) is considered easy and uneventful during the intraoperative period, as it is introduced under vision of laryngoscope; however, malposition of NGT has been reported, which can lead to serious complications. ${ }^{1,2}$

A 28-year-old female, with weight $55 \mathrm{~kg}$, was scheduled for laparoscopic cholecystectomy. After routine preoperative evaluation and monitoring, patient was induced and intubated with cuffed endotracheal tube no. 7 , then taken up on controlled ventilation. Nanogastric tube was introduced blindly and position was confirmed with air insufflation and epigastric auscultation.

Surgery was allowed to start. After 2 to 3 minutes, we noticed bellows of ventilator started collapsing, showing some leak in circuit or the ventilator. Patient was switched to manual ventilation and circuit was checked completely. An insufficient filling of reservoir bag kept us baffled about the site of leak. Circuit was again switched to controlled ventilation on ventilator and a decrease in the excursion of bellows was observed, showing a decrease in tidal volume again. A suspicion of a misplaced NGT led us to pull out the distal end and place it in a bowl of water. A surge of air bubbles with each expiratory movement confirmed the suspicion.

\section{${ }^{1}$ Professor, ${ }^{2}$ Assistant Professor}

${ }^{1}$ Department of Anesthesiology and Critical Care, Geetanjali Medical College \& Hospital, Udaipur, Rajasthan, India

${ }^{2}$ Department of Anesthesiology, Geetanjali Medical College \& Hospital, Udaipur, Rajasthan, India

Corresponding Author: Seema Partani , 14, Nakoda Complex Hiran Magri Sector 4, Udaipur, Rajasthan, India, Phone: +919414162150, e-mail: partaniseema@yahoo.in
A check of laryngoscopy gave us a visual confirmation of NGT in the trachea. On removal of NGT, the tidal volume improved and the ventilator bellows showed a normal excursion. Failure to identify a malpositioned NGT in the trachea may lead to serious pulmonary complications. Immediate confirmation in anesthetized or awake patient is essential before starting enteral feeding or medication. While inserting NGT, always confirm that the cuff of endotracheal tube is inflated (inadequate inflated cuff may direct NGT to trachea) and insertion should be under direct laryngoscope vision using Magill forceps. ${ }^{3}$

Epigastric auscultation is a very crude method of confirmation and may mislead us; $20 \%$ of false gastric confirmation by auscultation has been reported by Benya et al. ${ }^{4}$

Checking for air coming out of the distal end of NGT with every expiration and a decrease in tidal volume as witnessed by a decrease in excursion of bellows should increase our suspicion routinely about a misplaced tracheal NGT and confirmed by laryngoscopy. Various other methods like chest X-ray, ultrasonography, and $\mathrm{CO}_{2}$ colorimeter can confirm the position of NGT.

This event emphasizes the importance of sensitizing every anesthesiologist for quick diagnosis of malposition of NGT so as to avoid serious, fatal pulmonary complications because of negligence in such a simple procedure.

\section{REFERENCES}

1. Rassias AJ, Ball PA, Corwin HL. A prospective study of tracheopulmonary complications associated with the placement of narrow-bore enteral feeding tubes. Crit Care 1998;2(1): 25-28.

2. Roubenoff R, Ravich WJ. Pneumothorax due to nasogastric feeding tubes. Report of four cases, review of the literature, and recommendations for prevention. Arch Intern Med 1989 Jan;149(1):184-188.

3. Raut MS, Joshi S, Maheshwari A. Malposition of a nasogastric tube. Ann Card Anaesth 2015 Apr-Jun;18(2):272-273.

4. Benya R, Langer S, Mobarhan S. Flexible nasogastric feeding tube tip malposition immediately after placement. JPEN J Parenter Enteral Nutr 1990 Jan-Feb;14(1):108-109. 